\title{
AVALIAÇÃO DOS INSTRUMENTOS DO PROJETO “NOSSAS CRIANÇAS: JANELAS DE OPORTUNIDADES", SEGUNDO AGENTES COMUNITÁRIOS DE SAÚDE ${ }^{1}$ \\ HEALTH AGENTS” EVALUATION OF THE PROJECT INSTRUMENTS IN: “OUR CHILDREN - WINDOWS OF OPPORTUNITIES" \\ EVALUACIÓN DE LOS INSTRUMENTOS DEL PROYECTO “NUESTROS NIÑOS: VENTANAS DE OPORTUNIDADES", SEGÚN LOS AGENTES COMUNITARIOS DE LA SALUD
}

\author{
Juliana Martins', Maria De La Ó Ramallo Veríssimo3 ${ }^{3}$ Maria Agnes Oliveira ${ }^{4}$
}

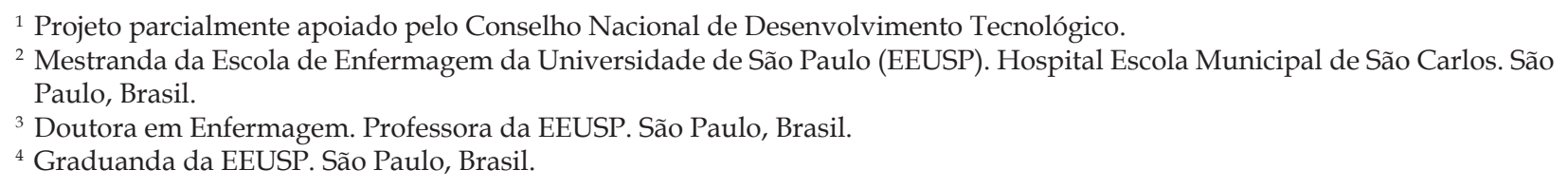

PALA VRAS-CHAVE: Avaliação. Promoção da saúde. Desenvolvimento infantil.
RESUMO: A cartilha e o manual "Toda hora é hora de cuidar" constituem tecnologias do Projeto "Nossas Crianças: janelas de oportunidades" direcionadas à promoção do desenvolvimento infantil. Esta pesquisa avaliativa, realizada em 2005/2006 com agentes comunitários de saúde, teve como objetivos: avaliar a aceitação e o uso da cartilha e do manual; identificar opiniões quanto ao conteúdo, formato e linguagem e; dificuldades e facilidades na implantação. A coleta de dados foi realizada em 17 Unidades Básicas de Saúde do município de São Paulo, através de grupos focais com 29 agentes comunitários e aplicação de questionários estruturados a 125 agentes. A análise temática de conteúdo evidenciou que eles consideram os materiais adequados e de boa qualidade, mas destacam dificuldades próprias das famílias e do processo de trabalho como barreiras a seu uso. Priorizam estratégias educativas verticais e tradicionais e o processo de capacitação influência de modo positivo a avaliação dos materiais.
KEYWORDS: Evaluation. Health promotion. Child development.
ABSTRACT: The guidebook and the support manual "It is always the right time for care" establish the technologies of the Project: "Our Children: Windows of Opportunities", which is geared towards promoting infantile development. The objectives of this evaluative research, conducted in 2005 and 2006 among Brazilian community health agents, were to assess acceptance and use of the guidebook and the support manual; to identify opinions about their content, format, and language; and to identify difficulties and facilities in using them. Data collection was carried out in 17 Public Health Care Clinics situated in São Paulo, Brazil through focus groups involving 29 agents and structured questionnaires, responded by 125 agents. The thematic content analysis showed that they consider the material appropriate and of good quality, but they highlight families' and working process difficulties as barriers to their use. They prioritize vertical and traditional educational strategies, as training schemes have a positive influence on the evaluation of materials.
PALABRAS CLAVE: Evalución. Promoción en salud. Desarrollo infantil.
RESUMEN: La cartilla y el manual de apoyo "Toda hora es hora de cuidar" constituyen tecnologías del Proyecto "Nuestros niños: ventanas de oportunidades" para promover el desarrollo infantil. Esta investigación de carácter evaluativo, realizada en 2005/2006, con agentes comunitarios de salud, tuvo como objetivos: evaluar la aceptación y el uso de la cartilla y del manual de apoyo; identificar opiniones acerca de sus contenidos, formatos y redacción; identificar las dificultades y facilidades para su implantación. La recolección de los datos ocurrió en 17 centros de salud comunitaria en la ciudad de Sao Paulo; 29 agentes participaron de grupos focales y 125 respondieron cuestionarios estructurados. El análisis temático indica que los participantes consideran los instrumentos adecuados y de buena calidad, pero destacan como barreras a su utilización, dificultades propias de las familias y del proceso de trabajo. Ellos priorizan estrategias educativas tradicionales y los programas de formación influencian de manera positiva a esa evaluación.
Juliana Martins

Endereço: R. Joaquim Filla, 55

13.690-000 - Jd. Paola, Descalvado, SP, Brasil.

E-mail: ju310781@yahoo.com.br
Artigo original: Pesquisa Recebido em: 29 de março de 2007 Aprovação final: 16 de janeiro de 2008 


\section{INTRODUÇÃO}

O presente estudo integra a pesquisa de avaliação da efetividade do projeto "Nossas Crianças: Janelas de Oportunidades" (Projeto Janelas), implantado desde 2003 em unidades do Programa Saúde da Família (PSF) do município de São Paulo, para ampliar as ações das equipes de saúde e instrumentalizá-las na promoção do desenvolvimento infantil.*

O Projeto Janelas tem como meta empoderar** as famílias na promoção do desenvolvimento infantil, mediante compartilhamento do conhecimento e ampliação de sua participação no processo de atenção à saúde da criança. Para isto, busca utilizar a capacidade de abrangência das equipes de saúde da família para abordar o desenvolvimento infantil, além da atenção biológica, enfocando também as dimensões social e humana relacionadas à saúde. Sua implementação pretende contribuir para os campos da promoção da saúde já propostos na Carta de Otawa, quais sejam: elaboração e implementação de políticas públicas saudáveis; criação de ambientes favoráveis à saúde; reforço da ação comunitária e desenvolvimento de habilidades pessoais. ${ }^{1}$

Sabe-se hoje que o cuidado inicial é decisivo e tem impacto duradouro sobre o desenvolvimento e a capacidade de aprender e de lidar com as emoções: a forma como a criança é cuidada interfere na formação e manutenção de suas ligações neurais. Existem períodos críticos durante os quais tipos específicos de aprendizado são melhores realizados e ocorrem quando o cérebro demanda um certo tipo de estímulo, para criar ou estabilizar algumas estruturas duradouras. Da mesma forma, há períodos em que experiências negativas ou ausência de estimulação podem levar a efeitos sérios e duradouros. ${ }^{2}$ Nesse sentido, o cuidado infantil deve ser de alta qualidade, isto é, imbuído de atenção e amor, capaz de gerar confiança e vínculo afetivo entre a criança e o cuidador. ${ }^{3}$

Entendendo isto, o Projeto Janelas lançou a cartilha, o manual de apoio "Toda Hora é Hora de Cuidar" 4 e a "Ficha de acompanhamento dos cuidados para a promoção do desenvolvimento infantil", para servirem como instrumentos utili- zados pela equipe de saúde da família na promoção do desenvolvimento infantil.

A cartilha foi elaborada para ser utilizada com as famílias com gestantes e crianças com até seis anos de idade, e aborda temas diversificados sobre o desenvolvimento infantil, em linguagem simples e com apoio de ilustrações. O manual oferece subsídios para o trabalho da equipe e o aprofundamento do diálogo, segundo os tópicos da cartilha, além de orientações práticas sobre como trabalhar com as famílias. A ficha busca sistematizar o acompanhamento da situação de cuidados oferecidos às crianças e foi elaborada para ser utilizada pelos médicos e enfermeiros da equipe de saúde da família nos contatos com as crianças.

Foram capacitadas pessoas indicadas pelas Unidades Básicas de Saúde (UBSs) para serem os multiplicadores do projeto. A capacitação teve um caráter inovador, foi realizada no formato de oficinas, nas quais foram adotadas estratégias participativas para discussão dos temas, tendo como referência o "Manual de apoio à cartilha Toda hora é hora de cuidar".

Tendo em vista que a implementação de toda nova proposta demanda acompanhamento e avaliação, com vistas à identificação de suas potencialidades e limites na prática assistencial, pergunta-se: em que medida o projeto Janelas é um instrumento de apoio da equipe de saúde, particularmente dos Agentes Comunitários de Saúde (ACSs), na promoção do desenvolvimento infantil?

O presente estudo enfocou a utilização do manual e da cartilha pelos ACSs, portanto, a efetividade dessa nova tecnologia na prática desses trabalhadores. Teve como objetivos: avaliar a aceitação da cartilha e do manual pelos ACSs; avaliar o uso referido desses instrumentos na sua rotina de trabalho; identificar dificuldades e facilidades encontradas na implantação de tais instrumentos; identificar suas opiniões quanto ao conteúdo, formato e linguagem da cartilha e do manual.

\section{METODOLOGIA}

Este estudo caracteriza-se como pesquisa avaliativa, com o objetivo de ajudar na tomada de decisão. A questão da avaliação em saúde,

\footnotetext{
* Chiesa AM, Solymos G, Fracolli L, Veríssimo MDLOR. Avaliação da implantação de novos instrumentos para o fortalecimento das ações de promoção do desenvolvimento infantil, na área de atuação do Programa Saúde da Família do município de São Paulo. [projeto de pesquisa] 2003.

**Adaptação para o idioma português do termo inglês empower, que se refere à ampliação do controle, poder e influência sobre a própria vida.
} 
enquanto objeto de investigação científica, foi consolidada a partir da década de 50 , sendo que no Brasil este tema ganhou maior abrangência apenas nos últimos anos. ${ }^{5}$

Avaliar é julgar e atribuir valor, com base em critérios previamente definidos. ${ }^{5-6}$ Sendo o julgamento um conceito operativo central da avaliação, "uma avaliação - uma 'boa avaliação' - deve julgar. Uma 'boa' e 'completa' avaliação julga e explica". 5:10

A avaliação, pode ser caracterizada de acordo com diferentes áreas especializadas: ${ }^{7} 1$ ) avaliação tecnológica em saúde: toma como unidade de análise uma tecnologia, no que diz respeito a suas dimensões técnicas e econômicas; 2) avaliação de programas em saúde: têm como foco de análise os programas de saúde; 3) avaliação, gestão e garantia de qualidade em saúde: tem como objetivo central a qualidade dos serviços.

De acordo com tal classificação, o presente projeto enquadra-se na área de avaliação tecnológica voltada às dimensões técnicas da tecnologia, pois visa avaliar a efetividade dos instrumentos, o manual e a cartilha, enquanto tecnologias utilizadas pelos ACSs para atuarem com as famílias e fortalecer aspectos da promoção da saúde infantil. No caso do Janelas, a tecnologia em foco é mediada pelo conhecimento, atitude, compromisso e responsabilidade do profissional, enquanto bases das práticas transformadoras na superação do modelo biomédico no cuidado de saúde. Enquanto dimensões de análise têm-se a adequação dos instrumentos em si e sua aplicação, avaliada pelas formas de utilização, facilidades e dificuldades. A avaliação foi norteada por indicadores quantitativos e qualitativos, e parâmetros de referência, ${ }^{6}$ elaborados ao início da investigação (Quadro 1).

O estudo foi realizado no período de 2005 a 2006, nas coordenadorias de saúde do município de São Paulo, nas quais o Projeto Janelas foi implantado até dezembro de 2004 . A população foi constituída pelos ACSs das unidades que implementaram o projeto. Participaram 26 UBSs que, do total de 653 ACSs, tinham 447 capacitados.

Para a coleta de dados, foram utilizados dois procedimentos: grupos focais, com o objetivo de apreender a percepção dos ACSs quanto à aceitação, utilização do material em sua rotina de trabalho, dificuldades e facilidades no uso dos materiais; e aplicação de um questionário estruturado sobre suas opiniões acerca do conteúdo, formato e linguagem do material.
O questionário foi encaminhado para o total dos 447 ACSs capacitados, e os grupos focais foram compostos por uma amostra sorteada de forma aleatória e proporcional ao numero de agentes em cada unidade de saúde, tendo sido convidados 20 ACS para cada um dos três grupos focais realizados nas regiões centro-norte, leste e sul da cidade.

Os dados qualitativos, obtidos através dos grupos focais e questões abertas do questionário, foram submetidos integralmente à análise temática de conteúdo. Os dados quantitativos foram armazenados e analisados utilizando o programa estatístico Statistical Package for the Social Sciences (SPSS), sendo calculadas a freqüência simples e a relativa para as variáveis categóricas nominais e ordinais.

O projeto foi aprovado pelo Comitê de Ética em Pesquisa da Secretaria Municipal de Saúde do município de São Paulo, sob o No 009/2005, e os participantes assinaram o Termo de Consentimento Livre e Esclarecido, no qual foram esclarecidos sobre os objetivos do projeto, forma de coleta de dados, garantindo o anonimato das informações e a liberdade para integrar o grupo de participantes.

\section{RESULTADOS}

Foram realizados três grupos focais, com a participação de 29 ACSs representando 17 UBSs das regiões Sul, Leste e Centro-Norte, sendo um grupo focal em cada região. No final da coleta de dados, obtivemos o retorno de 125 (28\%) inquéritos preenchidos completamente, representando 16 UBSs $(64 \%)$.

A maioria absoluta dos ACSs pertence a equipes do PSF, é do sexo feminino, trabalha na profissão há mais de três anos e utiliza a cartilha há mais de seis meses. Quanto à escolaridade, mais de $60 \%$ têm 11 anos ou mais de estudo, o que representa ter concluído o ensino médio.

Tendo por base a estrutura analítica elaborada no projeto, apresentam-se os resultados em relação às três dimensões propostas para a avaliação - Implantação do Projeto; Utilização dos instrumentos na rotina de trabalho; Adequação da linguagem, conteúdo e formato dos instrumentos. O Quadro 1 sintetiza os resultados, baseados nos indicadores e parâmetros propostos no projeto, e que serão apresentados detalhadamente à frente. 
Quadro 1 - Indicadores, parâmetros e resultados da avaliação da efetividade dos instrumentos do Projeto Janelas com os Agentes Comunitários de Saúde. São Paulo - SP, 2005-2006.

\begin{tabular}{|c|c|c|}
\hline Indicadores & Parâmetros esperados & Resultados \\
\hline $\begin{array}{l}\% \text { de ACSs capacitados nas } \\
\text { UBSs integrantes do Janelas. }\end{array}$ & $100 \%$ dos ACSs capacitados. & $\begin{array}{l}74,5 \% \text { dos ACSs capacitados (relativo ao nú- } \\
\text { mero total de agentes lotados nas UBSs). }\end{array}$ \\
\hline $\begin{array}{l}\% \text { de ACSs capacitados e que } \\
\text { utilizam o material. }\end{array}$ & $100 \%$ dos ACSs utilizam o material. & $\begin{array}{l}81,6 \% \text { dos ACSs capacitados utilizaram ou } \\
\text { utilizam o material (relativo ao total de agentes } \\
\text { capacitados e que responderam ao inquérito). }\end{array}$ \\
\hline $\begin{array}{l}\text { Formas de utilização dos ins- } \\
\text { trumentos. }\end{array}$ & $\begin{array}{l}\text { Utilização de acordo com o que foi } \\
\text { previsto na elaboração do projeto. } \\
\text { Busca formas de utilização mais efe- } \\
\text { tivas dos instrumentos, adequadas às } \\
\text { características de cada local. }\end{array}$ & $\begin{array}{l}\text { Maior utilização em visita domiciliar e grupos } \\
\text { educativos na UBSs e, alguns ACSs em ou- } \\
\text { tros locais da comunidade, como creche. }\end{array}$ \\
\hline $\begin{array}{l}\text { Facilidades e dificuldades } \\
\text { apontadas pelo ACSs no uso } \\
\text { dos instrumentos. }\end{array}$ & Facilidades superam dificuldades. & $\begin{array}{l}\text { Maioria: dificuldades encontradas no desen- } \\
\text { volvimento do projeto superam facilidades, } \\
\text { levando ao desuso do material. }\end{array}$ \\
\hline $\begin{array}{l}\text { Apresentar contribuições para } \\
\text { a prática. }\end{array}$ & $\begin{array}{l}\text { Relato de contribuições dos instru- } \\
\text { mentos na rotina de trabalho. }\end{array}$ & $\begin{array}{l}\text { Há relatos de contribuições dos instrumentos } \\
\text { na rotina de trabalho do ACS. }\end{array}$ \\
\hline $\begin{array}{l}\% \text { de ACSs que acham o ins- } \\
\text { trumento adequado quanto } \\
\text { ao formato, linguagem e con- } \\
\text { teúdo. }\end{array}$ & $\begin{array}{l}\text { Pelo menos } 2 / 3 \text { dos } A C S s \text { consideram } \\
\text { o formato, a linguagem e o conteúdo } \\
\text { dos instrumentos adequados. }\end{array}$ & $\begin{array}{l}\text { A cartilha é adequada quanto a: número de } \\
\text { páginas ( } 85,6 \%) \text {, tamanho }(90,4 \%) \text {, aspecto } \\
(88 \%) \text {, linguagem (89,6\%), ilustrações (92\%), } \\
\text { informações para família (93,6\%). } \\
\text { O manual é adequado quanto a: número de } \\
\text { páginas }(79,2 \%) \text {, tamanho }(80,8 \%) \text {, aspecto } \\
(83,2 \%) \text {, linguagem ( } 84 \%) \text {, ilustrações }(84 \%) \text {, } \\
\text { informações para o trabalho do ACS (84\%\%), } \\
\text { informações para o ACS (88\%). } \\
64 \% \text { dos ACSs consideram que não faltou } \\
\text { conteúdo na cartilha. } \\
70,4 \% \text { dos ACSs consideram que não faltou } \\
\text { conteúdo no manual. }\end{array}$ \\
\hline
\end{tabular}

\section{Implantação do Projeto Janelas com os ACSs}

Noventa e dois por cento dos ACSs afirmaram, nos inquéritos, terem sido treinados para usarem a cartilha. No entanto, $81,6 \%$ usou, mas atualmente não usa, e apenas $12,3 \%$ ainda usa a cartilha no dia a dia. Quanto ao manual, 2,1\% dos ACSs que receberam treinamento nunca o leram, 43,3\% leram alguns capítulos e 54,6\% leram completamente.

A maioria dos ACSs treinados para o uso da cartilha refere que o treinamento foi bom, pois ampliou seus conhecimentos para o trabalho com as famílias: o treinamento teve grande importância para o nosso trabalho (Região Sul); no treinamento as orientações foram claras e interessantes (Região Centro Norte).
Observam-se diferenças significativas quanto ao uso da cartilha, sendo que aqueles que foram treinados usam ou usaram mais a cartilha, e leram o manual em maior número que aqueles que não foram treinados.

\section{Utilização dos instrumentos do Projeto Jane- las na rotina de trabalho dos ACSs}

\section{Formas de utilização dos instrumentos}

Em várias UBSs os ACSs selecionaram as famílias que receberiam o material, porque o número de cartilhas enviadas não seria suficiente para todas, priorizando as "necessitadas", "em situações de risco", e com crianças cuja faixa etá- 
ria fosse mais adequada ao material: [...] como não dá para ser para todo mundo, eles pediram para cada agente escolher uma quantidade de famílias que têm mais fator de risco, que necessitam mais de orientação, cuidado especial, para estar trabalhando com estas famílias (Região Sul).

As UBSs distribuíram as cartilhas para as famílias durante as visitas e grupos educativos, durante o programa federal da bolsa família (Região Leste) e os ACSs relataram uso da cartilha com membros da própria família.

Quanto à dinâmica adotada para desenvolver o projeto, houve várias estratégias de uso da cartilha de acordo com a realidade de cada local: como instrumento durante as visitas domiciliares, em grupos educativos nas unidades e nas creches da comunidade, e na região Centro-Norte houve referência de trabalhos realizados com as crianças.

[...] a gente está passando principalmente nos grupos de gestantes, a gente tem passado e orientado as famílias [...] (Região Centro-Norte).

[...] este ano elas voltaram a fazer os grupos nas creches e na comunidade também, de pesagem [...] (Região Sul).

[...] juntei as crianças e disse vamos ler, eu consegui ler não foi um dia só, mais eu li porque se não a mãe...é interessante que as crianças prestaram atenção [...] (Região Centro-Norte).

A avaliação do uso da ficha não havia sido incluída nos objetivos porque esse instrumento deveria ser primordialmente utilizado pelos médicos e enfermeiros. Porém, em todos os grupos foi citado que a ficha muitas vezes só era preenchida pelos ACSs. Estes não encontram uma justificativa que considerem plausível para que tivessem assumido essa função, afirmando que o fizeram devido à indefinição quanto a quem competiria o preenchimento, sendo que em algumas unidades os ACSs receberam orientações de como aplicar a ficha com as famílias, como se fosse essa mesma a proposta: [...] na primeira vez quando vinha ficou indefinido quem preenchia, acabou ficando para os agentes preencherem as fichas e fazerem aquele questionário (Região Sul).

\section{Facilidades e dificuldades para o uso dos instrumentos}

Quanto às dificuldades para o uso dos instrumentos do Projeto Janelas, a maioria está implicada na implantação e desenvolvimento do projeto no âmbito de ação do próprio PSF e não especificamente no uso dos instrumentos.
As principais dificuldades referidas estão relacionadas às famílias, devido a inúmeros fatores como: condições precárias de vida das famílias que não têm possibilidade de atender às próprias necessidades; resistência ao trabalho desenvolvido pelos ACSs, que confrontam seus hábitos e valores próprios, desinteresse das famílias com questões referentes à saúde; desinteresse no projeto por já conhecerem o conteúdo, falta de tempo, não gostarem de ler; não reconhecerem benefício em aderir ao Projeto Janelas e pelo fato de quem cuida da criança não participar do projeto, já que as mães trabalharem e as crianças são cuidadas por outra pessoa, em creches e escolinhas.

[...] a cartilha é muito boa mesmo, ela é linda, gostaríamos todos nós agentes de saúde de conseguir mesmo mobilizar as famílias mais carentes para aderir tudo aquilo que está na cartilha, só que para aderir aquilo precisa ter condições financeiras [...] (Região Centro-Norte).

[...] voltando à cartilha, o ruim e o bom de trabalhar com a comunidade é que você tem que estar trabalhando sempre com princípios e valores de cada familia, [...] com hábitos, é muito difícil mudar hábitos, é difícil demais, e é o que mais a cartilha pede é a mudança de hábito (Região Centro-Norte).

[...] e a população não lê mesmo, não lê, não adianta [...] eles não lêem, alegam falta de tempo (Região Leste).

Também foram enfatizados pelos ACSs os problemas encontrados no dia a dia e relacionados a seu processo de trabalho no PSF e, em decorrência, no projeto. Eles sentem o trabalho desvalorizado tanto pela família como pela própria equipe, queixam-se da sobrecarga de trabalho, de problemas estruturais e do fato de estarem desenvolvendo o projeto Janelas sozinhos, sem a participação dos demais profissionais. O preenchimento da ficha pelo ACSs e a falta de capacitação também foram referidos como dificuldades.

[...] a mãe não dá importância para aquelas perguntas que eu fiz, os médicos e enfermeiros não dão importância para toda aquela anotação que você fez, então muitas vezes você se sente desmotivado [...] (Região Centro-Norte).

[...] nós estamos sobrecarregados de serviço, às vezes estamos fazendo alguma coisa que não é tão interessante que nem este projeto [...] (Região Centro-Norte).

[...] eu acho que tinha que ser um trabalho não só feito pelos agentes comunitários, tinha que ter o empenho maior de outras categorias também [...] (Região Centro-Norte). 
[...] nem espaço para trabalhar a gente tem [...] (Região Centro-Norte).

Como conseqüência destas dificuldades, alguns ACSs concluem que não conseguem implementar a proposta e contribuir para a melhoria da situação das crianças: [...] no geral, mas no caso do janelas que teve todo aquele treinamento, tudo direitinho, a gente tem a dificuldade de estar passando isso para frente, não em relação ao trabalho mas a própria população está deixando a gente mais pressionada e não ter como se passar para eles (Região Centro-Norte).

Por outro lado, nas regiões Leste e Sul, alguns ACSs referiram não terem encontrado dificuldades para trabalhar com o Projeto Janelas. As principais facilidades dizem respeito à receptividade das famílias em relação à cartilha, havendo melhor aceitação por mães adolescentes e de primeiro filho, por trazer um conteúdo novo para elas, por famílias carentes, e por famílias que estão dispostas a realizar as recomendações do ACSs. Também houve discussão sobre a receptividade das crianças, que sempre estão atentas e têm facilidades de transmitir as informações para outras pessoas.

Essas cartilhas foram bem mais aceitas por mães com o primeiro bebê, isso aí com certeza para elas é novidade [...] (Região Sul).

[...] a criança é tão comunicativa, tão esperta vai passar até para o primo, para os vizinhos, na escola [...] (Região Centro-Norte).

Ainda como facilidades no uso da cartilha, ACSs de todas as regiões apontaram o conteúdo e a linguagem acessíveis e apropriados para trabalhar com as famílias, informações que são do dia-a-dia do ACSs e da família, e o fato de poderem utilizar os instrumentos em atividades que já realizavam na sua rotina de trabalho: [...] é legal, a linguagem que usa, é simples e direta a linguagem da cartilha, sempre tem uma coisinha diferente igual a idéia da foto (Região Leste); [...] ela [a cartilha] é o dia-a-dia da família (Região Leste).

\section{Contribuições para a prática}

Em todas as regiões foram citadas contribuições do projeto na prática diária do ACS, principalmente em relação ao uso da cartilha e do manual. Em especial, destacaram o conteúdo abordado na cartilha no texto intitulado "O nó do afeto", como facilitador para abordar o tema de relacionamento com os filhos. Também foi destacado o espaço em formato de janela que existe na cartilha para a família personalizar seu material, como algo positivo.
[...] a cartilha eu acho muito boa, eu acho bacana, um apoio para a gente poder se especializar para poder passar para a população, então eu acho ela bem válida, eu acho material muito bom ajuda bastante na visita (Região Centro-Norte).

Eu acho que a cartilha ela traz um pensamento que a gente tem e não consegue expor para fora (Região Sul).

Em todos os grupos comentou-se sobre o manual, embora mais brevemente, e nem todos os ACSs possuíam um exemplar. Os ACSs dizem que o manual ensina a trabalhar a cartilha com as famílias, que é interessante, um complemento e tão bom quanto a cartilha.

\section{Adequação da linguagem, formato e conteú- do dos instrumentos do Projeto Janelas}

Os ACSs foram questionados, através dos inquéritos, sobre a adequação da linguagem, formato e conteúdo da cartilha e do manual "Toda Hora é Hora de Cuidar" (Quadro 1).

O número de páginas e o tamanho da cartilha e do manual foram considerados adequados: poucas páginas, simples, didática, resumidas, explicativas, abrangendo todos os assuntos cotidianos e necessários para orientação; o pequeno volume facilita o desenvolvimento do trabalho, pois é fácil de manusear. Observou-se que o número de páginas do manual foi considerado adequado em maior número por aqueles que foram treinados, usaram a cartilha e conheciam e leram o manual. O tamanho do manual também foi considerado adequado em maior número por aqueles treinados, com maior grau de escolaridade e que conheciam o material.

$O$ aspecto da cartilha foi considerado atrativo e bem organizado, por apresentar um assunto de cada vez, despertar a atenção das crianças devido ao seu colorido e ao seu aspecto infantil, ser feita de material de qualidade. $\mathrm{O}$ aspecto do manual também foi considerado adequado por ser bem organizado.

Em relação aos conteúdos da cartilha e do manual, a maioria dos ACSs respondeu que são importantes e que não faltou nenhum conteúdo. Os ACSs consideram as informações da cartilha importantes para as famílias, já que orientam, ajudam-nas no dia a dia, estimulam o cuidado e a reunião da família para leitura e mostram a elas as possibilidades de como cuidar dos filhos. Também relatam que as informações complementam e apóiam o trabalho dos agentes, trazem 
informações educativas, atualizadas, completas, esclarecedoras, falam da realidade e de assuntos que interessam às famílias. Quanto à importância das informações do manual, justificam que trazem um conteúdo necessário, enriquecem seus conhecimentos, ajudam a orientar e esclarecer dúvidas das famílias, e contribuem de forma direta para o desenvolvimento do trabalho dos agentes, pois melhoram seus conhecimentos.

Alguns ACSs citaram assuntos que consideram ter faltado na cartilha e no manual, por exemplo: gestação, amamentação, primeiros socorros, drogas, entre outros.

Os ACSs afirmam que a linguagem da cartilha é compreensível e adequada às famílias, por ser simples, clara, popular, objetiva e aumentar o interesse na leitura. A linguagem do manual também foi considerada adequada para os seus fins, por ser simples, objetiva, esclarecedora, explicativa, clara, popular, com letras legíveis, o que facilita o entendimento e a leitura para qualquer pessoa independente do nível de escolaridade. Nota-se que a linguagem do manual foi considerada adequada em maior número por aqueles que receberam treinamento e conheciam o manual.

As ilustrações da cartilha e do manual foram consideradas adequadas por ajudarem a compreender o texto, mostrar o que este quer dizer, ajudar na sua interpretação e em seu entendimento, esclarecendo-o e relacionando-o com os objetivos propostos, o que contribui para o desenvolvimento do trabalho dos ACSs. Ainda apontam o fato de auxiliarem, as pessoas que têm dificuldades com a leitura ou não sabem ler, a compreenderem o texto. Foram consideradas adequadas em maior número por aqueles que receberam treinamento.

\section{Sugestões e comentários}

As sugestões dos ACSs enfatizam a necessidade de mais material, maior divulgação, ampliação para outras áreas, capacitação e acompanhamento das atividades: [...] eu acho que tinha que investir mais neste projeto [...] (Região Centro-Norte).

É um trabalho muito bonito, para a gente estar trabalhando desenvolvendo realmente este trabalho precisa capacitar melhor, é um trabalho bonito (Região Leste).

\section{DISCUSSÃO}

Várias mudanças de ordem política e administrativa, como mudanças nas chefias das coordenadorias e reorganização de áreas de abrangência das unidades, ocorreram no cenário de implantação do Projeto Janelas e posteriormente no cenário de avaliação. Em decorrência disto, ele não foi, ainda, incorporado como política pública de promoção à saúde da criança, ficando sua implementação na dependência do esforço e do compromisso de profissionais que mantiveram a proposta com as famílias, por reconhecerem sua importância.

Observando-se os resultados de forma geral, percebe-se que os ACSs consideram os instrumentos cartilha e manual como adequados e de boa qualidade, mas detém-se nas dificuldades de sua utilização, em grande parte explicadas pelas mudanças contínuas na organização dos serviços, conforme apontado anteriormente.

As mesmas razões podem explicar o fato de não terem sido capacitados $100 \%$ dos ACSs, conforme esperado, e a diminuição no uso do material, lembrando que apenas $12,3 \%$ usa a cartilha no dia a dia. Entretanto, possivelmente o enfraquecimento das ações do projeto se deve à sua não incorporação ao cotidiano de trabalho nas unidades. Isto é evidenciado quando os agentes afirmam realizarem tais ações de forma solitária, sem retaguarda nem continuidade de formação para superação das dificuldades encontradas.

Chama a atenção o fato de haver ACSs que utilizam a cartilha sem terem recebido o treinamento nem conhecer o manual, bem como ACSs capacitados, mas que também não conheciam o manual. Considerando que a grande mudança do projeto não é o instrumento em si mesmo, mas as formas de utilizá-los com a população, abordadas no processo de capacitação bem como no manual, isto leva a pensar o quanto esta nova tecnologia está sendo usada de forma adequada e trazendo os potenciais benefícios para a população. A importância do treinamento confirma-se quando aparecem as diferenças significativas de opiniões entre aqueles que receberam o treinamento, usam a cartilha e conhecem o manual.

$\mathrm{O}$ uso dos instrumentos durante as visitas domiciliares, em grupos educativos realizados nas UBSs, e em menor número, em creches e grupos com crianças maiores, demonstra que os ACSs envolvidos com o projeto foram criativos na utilização dos instrumentos. Entretanto, na maioria dos depoimentos, notou-se a priorização de estratégias educativas verticais e tradicionais, como a seleção dos temas e a leitura do material pelo ACSs, sem relatos de uso de estratégias que propiciassem maior participação das famílias. 
Embora o PSF tenha sido proposto como uma nova metodologia assistencial, as atividades educativas ainda são predominantemente impositivas, chegando às vezes ao autoritarismo, restringindo-se as possibilidades de conversa com exposição e confrontação de valores, como tradicionalmente ocorre na assistência biomédica. ${ }^{8}$ O Projeto Janelas foi elaborado com o objetivo de contribuir para mudar este modo de trabalhar com a informação. Previa-se que a cartilha fosse um instrumento para a equipe de saúde iniciar a discussão de determinado assunto com a família e, a partir dos conhecimentos trazidos por esta família, trabalhar com ela os conceitos, as práticas de cuidado e formas de resolver situações cotidianas, desta forma, apoiando a família e fortalecendo-a em seu papel no cuidado infantil.

Aparecem dificuldades significativas para trabalhar a cartilha com as famílias, identificadas pelos agentes como devidas às suas condições precárias de vida, resistência às atividades, desinteresse e não reconhecimento de potenciais benefícios do projeto, falta de acesso ao cuidador rotineiro das crianças, como as que ficam em creche.

Trabalhar com uma população com desigualdades sociais tão marcantes, mostra a dificuldade que o ACS encontra em desenvolver seu trabalho não só no Projeto Janelas e sim no próprio PSF, “... no trabalho do agente está incluída uma série de situações para a qual a área da saúde ainda não desenvolveu um saber sistematizado e instrumentos adequados de trabalho e gerência, desde a abordagem da família, o contato com situações de vida precária que determinam as condições de saúde, até o posicionamento frente à desigualdade social e a busca da cidadania". 8:180

O difícil acesso ao cuidador rotineiro da criança, na maioria das vezes, ocorre pelo fato das mães trabalharem e deixarem as crianças na creche ou com outro cuidador. Atualmente, a cada ano aumenta o número de mulheres que trabalham, segundo dados do Instituto Brasileiro de Geografia e Estatística. Em 2006, 44,4\% da população economicamente ativa na região metropolitana de São Paulo era composto por mulheres. ${ }^{9}$

Neste contexto, e acreditando que a promoção do desenvolvimento infantil é um compromisso da sociedade e não só da família, é necessário que o ACS e as equipes de saúde busquem novas estratégias para desenvolver o projeto com as mães e também com outros cuidadores. Algumas iniciativas nesse sentido foram realizadas nas regiões Leste e Sul, mediante grupos educativos nas creches com os "outros" cuidadores da criança, e também com utilização do espaço da creche para trabalhar com os pais durante os finais de semana.

Outra dificuldade apontada foi o fato da população não ter o hábito de leitura. Mais uma vez está explicito o conceito que o ACS traz em relação à educação em saúde e a não incorporação do modelo de educação proposto pelo Projeto Janelas, na qual a leitura é apenas um dos recursos disponíveis e não o único e mais importante.

Outro assunto que gerou grande discussão diz respeito ao processo de trabalho do ACS no PSF e no projeto. Os ACSs sentem seu trabalho desvalorizado tanto pela família como pela própria equipe, queixam-se da sobrecarga de trabalho, de problemas estruturais e do fato de desenvolverem o Projeto Janelas sozinhos, sem a participação dos demais profissionais.

Estudo realizado com a equipe multiprofissional do PSF concluiu que existe, no entender de alguns profissionais, um relacionamento hierárquico entre os membros da equipe de saúde e o ACS não é visto como membro da equipe. Isto tudo dificulta a integração, sendo o relacionamento interpessoal a principal fonte de conflitos entre os integrantes da equipe. ${ }^{10}$

Mesmo frente às dificuldades referidas em todas as regiões, os ACSs manifestam a importância de insistir no projeto e sugerem ampliá-lo para creches e escolas, pois acreditam que a proposta é importante e poderia contribuir para melhorar a situação de saúde infantil. Notamos que os ACSs, com o uso dos materiais, sentem-se fortalecidos para apoiar as famílias na promoção do desenvolvimento infantil.

Em todas as regiões foram citadas contribuições do projeto na prática diária do ACS, referindo que a cartilha contribui no processo de trabalho, ajudando-o a trabalhar os conteúdos com as famílias, e os instrumentos foram avaliados de forma positiva quanto à linguagem, conteúdo e formato.

A avaliação positiva quanto à adequação do material e as dificuldades encontradas na prática subsidiam a discussão sobre eficácia e efetividade. A eficácia é o efeito de uma intervenção em situação experimental e a efetividade é o efeito da mesma em sistemas operacionais. ${ }^{11-12}$ Pode-se então afirmar que os instrumentos do Projeto Janelas para os ACSs são eficazes, mas não são efetivos, uma vez que são avaliados como adequados e importantes para a sua prática (eficaz), mas, quando 
aplicados na realidade, as dificuldades superam as facilidades (efetividade).

Por fim, o desuso do material e as dificuldades apontadas ocorreram por problemas organizacionais e intrínsecos do serviço de saúde, tais como mudanças políticas, falta de capacitação dos profissionais, falta de acompanhamento das ações, influências do modelo biomédico, que são questões que ainda são os desafios do SUS em todo o país. ${ }^{13}$

\section{CONSIDERAÇÕES FINAIS}

O estudo possibilitou alcançar os objetivos propostos e contribuir para a avaliação do Projeto Janelas. Pode-se afirmar que a cartilha e o manual "Toda Hora é Hora de Cuidar" são tecnologias importantes e adequadas para a equipe de saúde na promoção do desenvolvimento infantil, em especial para o ACS, por instrumentalizar e sistematizar as ações destes profissionais, que se sentem legitimados para tratarem desse tema com as famílias. Os ACSs consideram que o uso dos instrumentos traz benefícios para as famílias, uma vez que estas são fortalecidas e contribuem de forma singular na promoção do desenvolvimento infantil.

Entretanto, a efetividade do projeto ainda não pode ser confirmada, dadas as dificuldades e os desafios de implantação do PSF que ainda não foram superados e influenciaram diretamente a incorporação das ações propostas, bem como do próprio referencial, pelas equipes de saúde.

A foco de inovação do Projeto Janelas não se concentra no material em si, mas na abordagem e estratégias de cuidado propostas, na adequação dos conceitos ao modelo de educação e promoção da saúde, e no processo de formação permanente e acompanhamento das atividades desenvolvidas. Assim, compreende-se que sua utilização tenha se mantido mais prolongadamente em unidades onde há maior sintonia com essa abordagem.

Acredita-se que estudos dirigidos a tais cenários poderão contribuir para análise e compreensão das possibilidades e limites da proposta e dos instrumentos mais propriamente.

\section{REFERÊNCIAS}

1 Heidmann ITSB, Almeida MCP, Boehs AE, Wosnu AM, Monticelli M. Promoção à Saúde: trajetória histórica de suas concepções. Texto Contexto Enferm. 2006. Abr-Jun; 15 (2): 352-8.
2 Shore R. Repensando o cérebro: novas visões sobre o desenvolvimento inicial do cérebro. Trad. IR Brasil. Porto Alegre (RS): Mercado Aberto; 2000.

3 Veríssimo MLOR. O desenvolvimento infantil e o cuidado da criança pela família. In: Nossas Crianças: Janelas de Oportunidades. São Paulo (SP): Secretaria Municipal de Saúde/Programa Saúde da Família; 2002.

4 Secretaria Municipal de Saúde, Programa da Saúde da Família. Toda hora é hora de cuidar. [Manual de apoio do Projeto "Nossas Crianças: Janelas de Oportunidades"]. São Paulo (SP): SMS/PSF; 2002 [acesso em: 2007 Jul 07]. Disponível em: http:// www.ee.usp.br/pesquisa/grupromo/

5 Nemes MIB. Avaliação em saúde: questões para os programas de DST/AIDS no Brasil. [Coleção ABIA: Fundamentos de Avaliação, n.1]. Rio de Janeiro (RJ): Associação Brasileira Interdisciplinar de AIDS; 2001.

6 Tanaka OY, Melo C. Avaliação de Programas de Saúde do Adolescente: um modo de fazer. São Paulo (SP): EDUSP; 2001 [acesso em 2004 Nov 16]. Disponível em: http://www.adolec.br/bvs/ adolec/P/textocompleto/adolescente/indice.htm

7 Novaes HMD. Avaliação de programas, serviços e tecnologias em saúde. Rev. Saúde Pública. 2000; 34 (5): 547-59.

8 Silva JÁ, Dalmaso ASW. Agente comunitário de saúde: o ser, o saber, o fazer. Rio de Janeiro (RJ): Fiocruz; 2002.

9 Ministério do Planejamento, Orçamento e Gestão (BR), Instituto Brasileiro de Geografia e Estatística. Pesquisa mensal de emprego: dezembro de 2006, região metropolitana de São Paulo [acesso em 2007 Fev 07]. Disponível em: http://www.ibge.gov.br

10 Seabra DC. O agente comunitário de saúde na visão da equipe multiprofissional [dissertação]. Ribeirão Preto (SP): USP/EERP; 2006.

11 Silva LMV. Conceitos, abordagens e estratégias para a avaliação em saúde. In: Hartz ZMA, Silva LMV, organizadores. Avaliação em saúde: dos modelos teóricos à prática na avaliação de programas e sistemas de saúde. Salvador (BA): Fiocruz; 2005.

12 Schramm FR, Escosteguy CC. Bioética e avaliaçõa tecnológica em saúde. Cad. Saúde Pública. 2000 OutDez; 16 (4): 951-61.

13 Ministério da Saúde (BR), Conselho Nacional de Saúde. O desenvolvimento do Sistema Único de Saúde: avanços, desafios e reafirmação dos seus princípios e diretrizes [Série B: Textos Básicos de Saúde]. Brasília (DF): MS; 2003.

14 Chiesa AM. Autonomia e resiliência: categorias para o fortalecimento da intervenção na atenção básica na perspectiva da Promoção da Saúde [tese]. São Paulo (SP): USP/EEUSP; 2005. 